\title{
Combined Approaches in Automatic Page Clustering FOR CONTENT CONVERSION
}

\author{
BOIANGIU, C. A. \& CANANAU, D. C.
}

Abstract: The purpose of this paper is to present a model for separator detection using the Delaunay triangulation and a common sampling algorithm based on a triangular filter. By using a sampling algorithm, the blur effect is created and together with the output triangles, obtained from the modified Delaunay algorithm, the separators can be determined after processing.

Key words: delaunay triangulation, filter, contour, separators
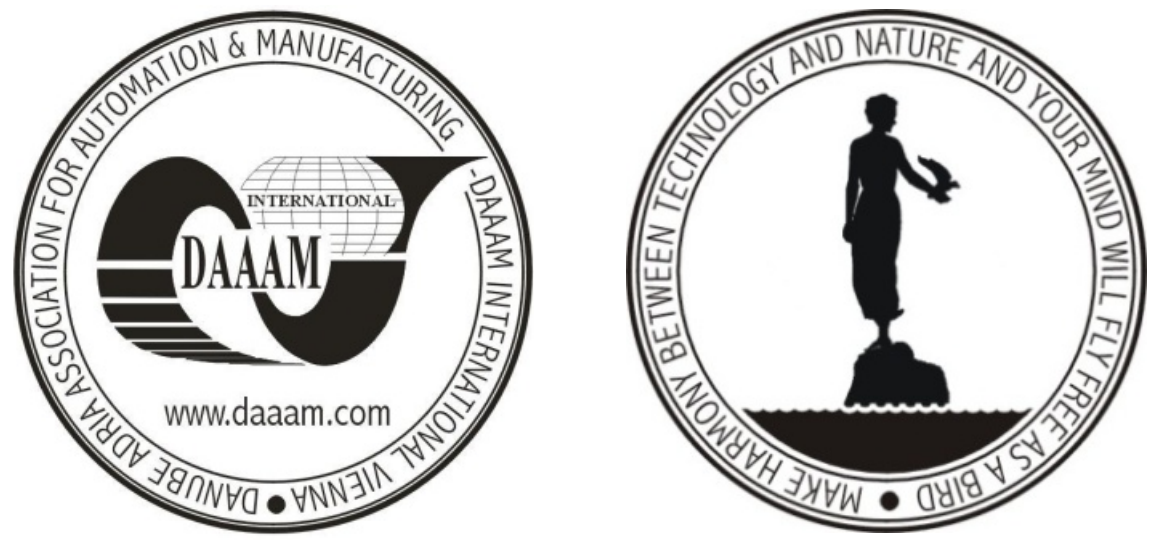

Authors' data: Lecturer PhD. Eng. Boiangiu, C[ostin] A[nton]; Eng. Cananau, D[an] C[ristian], University „Politehnica“ of Bucharest, Splaiul Independentei 313, Bucharest, Postal Code 060042, Romania, costin.boiangiu@cs.pub.ro, dan_cananau@yahoo.com

This Publication has to be referred as: Boiangiu, C[ostin] A[nton] \& Cananau, D[an] C[ristian] (2009). Combined Approaches in Automatic Page Clustering for Content Conversion, Chapter 31 in DAAAM International Scientific Book 2009, pp. 289-304, B. Katalinic (Ed.), Published by DAAAM International, ISBN 978-3901509-69-8, ISSN 1726-9687, Vienna, Austria

DOI: $10.2507 /$ daaam.scibook.2009.31 